\title{
Multi-layered urban strategies to foster the Smart Cities development
}

\author{
E. Antonini, S. O. M. Boulanger \& J. Gaspari \\ Department of Architecture, University of Bologna, Italy
}

\begin{abstract}
In the last decade, the Smart City model has emerged as a reference concept in shaping the city of the future, mainly by strengthening the connections between grids, Information and Communications Technologies (ICT), governance and people. In this framework, architecture and the building scale seem to be left in the background, as a residual aspect compared to the role that grids and ICT are expected to play. However, the integrated design at building and district scale is an ineluctable backbone of the implementation process, allowing further actions to achieve effective and innovative paths toward a smarter city. The paper aims to point out the interrelations between the Smart City concept and the key parameters needed to manage complex urban environment in real conditions. An on-going research activity lead in the city of Bologna is summarized, in which the cooperation between the Municipality, the Department of Architecture, local stakeholders and companies is aimed at combining hardware and software more effectively. The goal is to bridge the gap between physical and virtual components, by setting methods and tools to couple technical aspects with socioeconomic issues that usually feed the renovation processes. It means creating a tool able to provide and manage information concerning the interactions between the buildings within the district and the urban fabric at city level. The tool must perform the integration between ICT and conventional building components, by collecting data, mapping relations and identifying both conflicts and synergies. A layered structure is defined in order to cover the most influencing parameters as well as key crosscutting issue that may influence the smart city development and effectiveness. The expected benefits mainly concern public administration and policy makers, to which the tool may provide a support in maximizing the impacts and the exploitation potential of the innovations at city level.

Keywords: smart city, urban strategies, district, building efficiency, monitoring, ICT.
\end{abstract}




\section{Introduction}

The access to a large palette of emerging technologies is becoming of vital importance for human being, especially in urban contexts. However, inhabitants expect to obtain not only occasional and individual advantages (and even less an increasing complexity), but also cities and environments more responding to the fast change in people needs and lifestyles, and more effective in providing perceptible benefits and useful purposes [1-3]. In addition, the climate change needs to be adequately faced in urban contexts in order to decrease both vulnerability and energy consumption. In particular, it is expected that Europe reduce $\mathrm{CO}_{2}$ emissions by $30 \%$ until 2030, and fossil fuel based energy consumption and related greenhouse gas emissions by $80-90 \%$ until 2050 [4]. An on-going research activity at the Department of Architecture of University of Bologna is trying to provide a systemic vision and methodology to foster the adoption of effective strategies and solution to improve the development of smart city model engaging the key stakeholders.

\section{Specific context and background framework}

\subsection{Main challenges for the Smart Cities development and advance beyond the state of the art}

The crisis of the development models in the contemporary city is nowadays evident, not only for experts, planners and architects, but also for the population and citizens that have to face new and challenging issues in everyday life [5-7]. Traffic congestion, the poor quality and the carelessness of most of the suburb building stock, the pollution level, as well as the effects of climate change on comfort and safety conditions of the built environment includes a number of key design topic investing several cities across Europe. The design of those environments and, overall, their management are often the result of economics and political constraints, rather than of balanced architecture dictates. In addition, the contemporary city is required to provide adequate answer to:

- the European regulations, imposing a substantial reduction of emissions, an overall improvement of energy efficiency and environmental urban conditions;

- the pressure of the market that, despite the impacts of the recent financial crisis, continue to offer new products and application in the sector of ICT aimed at making people's everyday life more smart, while involving at same time the urban environment and its large scale dynamics (i.e. georeferencing apps., etc.);

- the large number of obsolete buildings and neighbourhoods, whose very poor energy and environmental performances require cost-effective measures at least for security, network functionality and mobility reasons;

- the "dormitory suburbs" that require revitalization process based on mixed use; 
- the constant pressure of urbanization, which increases the land use, even when this is not required to shape the city development process [8];

- the increasing demand of resources, due to population and urbanization growth [3].

Smart City issue arises and feeds into this context of economic and societal crisis and of widespread shortage of wellbeing and physical resources. The Smart City concept try to give an answer to all those problems [9], by leading cities into innovative urban planning with the large use of technologies in order to make cities cleaner, safer, more efficient and more comfortable [5].

\subsection{Key objectives of Bologna Smart City challenge}

Bologna, the capital of Regione Emilia-Romagna, is the $7^{\text {th }}$ most populous Italian city (386,298 inhabitants, with a density of $2,742.43 \mathrm{hab} / \mathrm{m}^{2}$ ), with a metropolitan area of about 1 million inhabitants. The city has a significant endowment of transport infrastructure (airport, train station on the new highspeed network, the intersection of three highways), it hosts the oldest university of the west world and one of the largest in Europe (80,000 students) and it ranks among the top 10 (out of 100) Italian cities for income. According to Smart City Index 2014 [10] and ICityRate ranking [11], Bologna is one of the most active Italian cities in developing integrated smart approaches at urban scale, mainly in the fields of Smart Health, Smart Education and Sustainable Development. As emerges from these studies, the Bologna approach is one of the most balanced in Italy, thanks to both the implementation of strategies involving all the main urban challenges and the synergies between University and Municipality. The research project, jointly developed by the two Institutions, is mainly focused on building/district integration, aiming to be an active part of a smarter urban system, by exploiting grids and technological devices to boost and support the transition process.

\subsection{Smart cities as layered entities: cross cutting topics}

The complexity and holistic vision needed by an effective smart model are the main aspects that have considered drafting Smart City strategies for the city of Bologna. Since Smart City is defined as the combination of 6 main topics: economy, people, governance, mobility, environment and living [12] a "Triple Helix Model" can represent its basic framework, consisting of a connection among stakeholders, and in particular among university, industry and government.

The project is developed assuming the Smart City conceptual model as a multi-layered structure and considering the following key design issues:

- $\quad$ situations that occur in all layers must be known and related as easily and efficiently as possible, by a tool able both to boost the implementation of projects into reality and to analyse the interrelations in a holistic way;

- the tool must also operate as a simulator, able to assess the sustainability of possible solutions for the renovation of the built environment, by checking their combined effects on all the layers. 
A set of both functional and technological layers has been established to apply within the research, as described below:

- an object layer, describing the objects in which the smartness could be applied: mobility, environment, districts, grids, buildings;

- an actor layer, describing all actors involved into the Smart City process, with their interrelations: universities, industry, government, people, service providers, associations, start-up companies, etc.;

- a technological/monitoring layer, describing all technologies involved into the project, aiming at monitoring the implementation of the project and its effects;

- a policy/economic layer, describing all big scale measures that a city have to implement in order to make the project real: funding, governance actions, regulations, etc.

In order to perform the expected "smart" effects at city scale, all those layers have to communicate and interact. The connection can be assured by using a common tool, relating all stakeholders and all layers, or trough a governance approach, in which the municipality or another stakeholder take the role of coordinator.

The project proposes the implementation of a technological tool, assuming that a shared model make the integration more sustainable even over a long period of time.

This platform aims at simplifying a complex system into several simpler parts, defining a clear and organized structure in order to manage the complexity and to maximise the impacts of potential benefits.

New tools are needed to bridge the gap between conventional approaches to building renovation and a multi-perspective vision needed to create a real low carbon environment. To make possible such "crossing overview" knowledge and experiences acquired in the last decade must be integrated and capitalized into an operational environment where effective (and specific) solutions can be selected, simulated and assessed. The development of systematic assessment strategies and tools able to predict or address the main impacts of the proposed actions (efficiency, urban quality and environmental sustainability) at different scale is a great challenge that the research must cope.

\section{The Smart City model for shaping the city of tomorrow}

The research focuses on three main objectives, which represent the key actions for shaping the smart city model: buildings, in which smart and sustainable strategies can be applied whit the specific aim to improve people comfort; district, in which the space between buildings is considered the mean to boost the transition of urban context; instruments and tools, aiming to better understand processes and buildings behaviour in a long term dimension.

\subsection{The building scale as place of key transformation processes}

The renovation of existing building stock is a key challenge for the EU, to meet the ambitious goal of decarbonisation: according to Roadmap to 2050, 
greenhouse gas emissions are expected to be reduced by $80-95 \%$ compared to 1990. The building sector is estimated to be responsible for $40 \%$ (or more, depending on the calculation criteria and the considered boundaries) of the total energy consumption in the EU [13]. Despite several studies [1, 3, 14] advocate the potential positive effects of refurbishment of the existing building stock, several technical and non-technical barriers occur and comprehensive strategies and measures focusing on the interactions at the district scale are still lacking. Despite the great efforts that have been made in the past for improving the energy efficiency of "individual buildings" and achieving effective renovation actions at building scale, a comprehensive methodology capable of considering the interactions between buildings at district/neighbourhood scale is still not available. The main challenges are:

- complexity;

- variability;

- $\quad$ fragmentation of building life cycles;

- $\quad$ addressing building end user awareness.

In order to meet this challenges, the project proposes an integrated approach for refurbishment, in which the design process is based on an iterative approach having options carefully evaluated according to specific parameters and the coherence with the action as a whole. Each step of the design process involves experts of different disciplines, which tackle the issue according to their perspective, figure 1. Buildings are defined as a key element for the development of the city's smartness, being urban nodes in which all layers can communicate and interrelate.

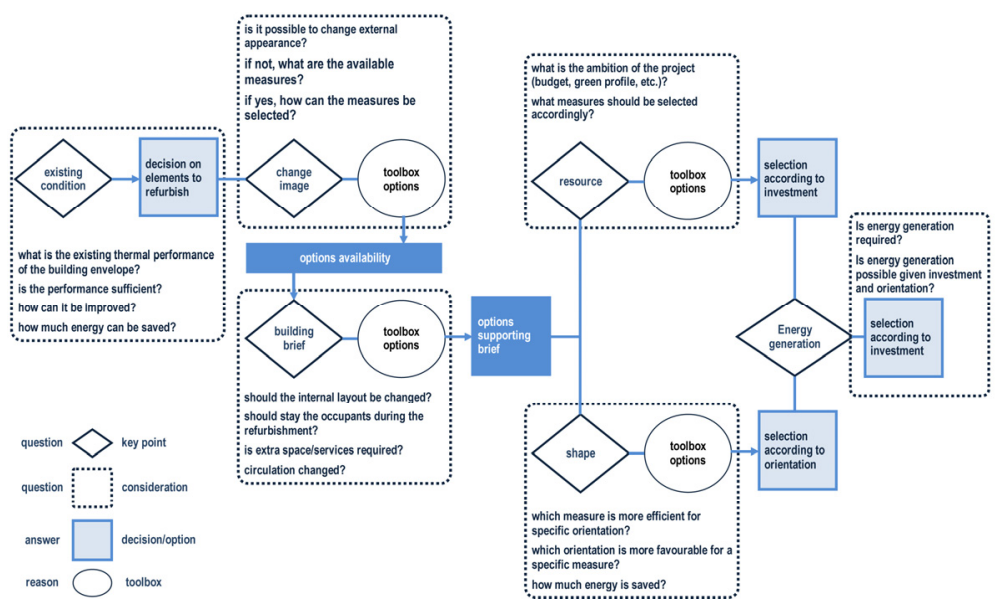

Figure 1: Example of the methodology adopted to define the main actions to be included in the interoperable platform aimed at addressing/supporting multi-player decision processes.

The key importance of buildings is defined by different actions into the project: 
- $\quad$ the refurbishment, starting from social housing and public buildings, which considers the renovation of façades and the implementation of architectural devices as means to reduce overheating in summer and to improve solar gains in winter. The refurbishment of building is pursued by the implementation of passive solutions as well as with the integration of innovative RES solutions, both thermal and PV;

- the installation of sensors and automated devices able to collect data and monitoring the building behaviour, in order to increase the end-users consciousness and the adoption of positive behaviour toward a more sustainable lifestyle.

To achieve those actions, the project proposes to stakeholders a Renovation Kit, in which different standardised solutions are provided according to main geographical contexts and climate profiles. The project assumes that despite it not being possible to provide a unique design solution in all contexts, some standardised configurations could be a good starting point to develop specific tailored responses. Building refurbishment projects have a vital importance for a sustainable future and they cannot be efficiently managed by current oneproblem-one-solution technical approach. The Refurbishment Kit developed by the project, instead, aggregates solutions and renovation options according to the level of refurbishment that the end-user wishes to reach. The innovation potential of this tool is based on the opportunity of classifying refurbishment works in a limited number of kits, delimiting their scope and thus the range of possible technical solutions to apply, the involved agents and the request budget. Although the uniqueness of each building will be considered at the end of the process, to define the specific refurbishment works to be done, the Renovation Kit gives the opportunity to boost refurbishment by cataloguing several renovation solutions.

\subsection{The district as nodes of multi-layered smart city}

To be "smart" the whole city must act in a holistic way. However, this integrated behaviour requires an effective management of a wide number of variables and the combined effect of multiple dynamics, affecting each part forming the urban system.

Since the problem in its whole dimension was perceived as not approachable, the traditional approach to the urban management operates on each part by specialized tools and sectorial strategies. The intermediate dimension of the district scale offers a more interesting issue: all actors of the process could be involved, both in economic and social way (for example by implementing fablab or co-creation activities for the development of the district) and all technologies could have their application. To implement the Smart City process, a district or a set of district could be an easier scale of intervention, also to made tests and pilot projects.

A comprehensive district approach to renovation offers the most likely and effective scale at which the overall goals of a sustainable city can be addressed. District and buildings refurbishment could be a key area where the impact of innovation is expected to create socio-economic changes, including tools and/or 
solutions that allow a smarter approach to energy efficiency principles, through the adoption/integration of ICT empowering communities and end-users, figure 2.
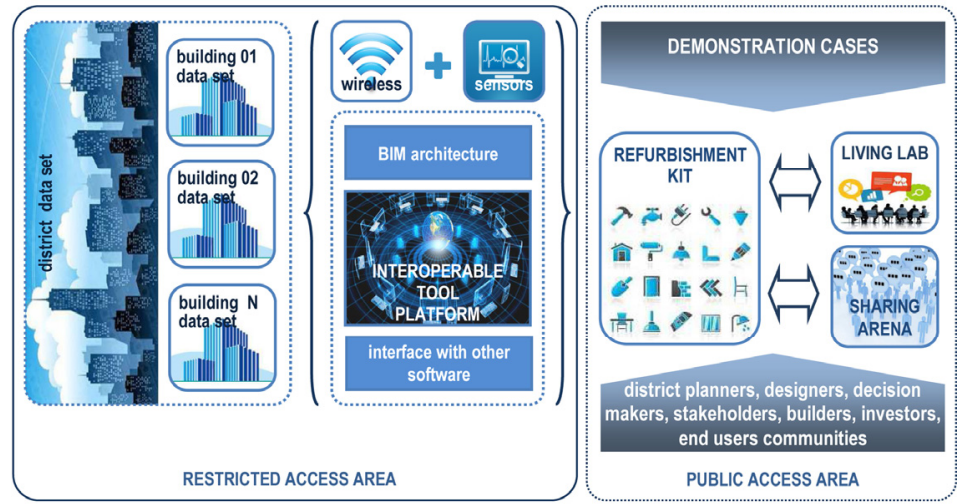

Figure 2: The interoperable platform architecture is based on a strong connection between ICT tools and the buildings in order to have a feedback at district/city level. The platforms enable the refurbishment kit to be applied in several demonstration cases involving the stakeholders by living labs and a dedicated discussion area.

In this framework, not only the building in itself but also the shared space between buildings assume a great importance, and the connections between indoor and outdoor conditions, the district with its grids, as well as the different actors of the refurbishment actions.

An integrated approach on the refurbishment at district level has to consider different steps:

- to define key design parameters and interrelation between buildings at district scale, by the mean of clear and measurable factors (considering the specific climate conditions), to develop mitigation actions improving comfort conditions;

- to define design and management settings to be applied in the operational environment: design strategies (at building and district scale), technical solutions (for heating/cooling, ventilation, domestic hot water production including renewable energy sources, thermal storage, electrical energy production and distribution, building envelope systems, building components), construction processes, building management system/district management system;

- to combine energy efficiency with cost-effective standards at district level;

- to create a refurbishment products and solutions production/supply chain;

- to create adequate geo-clusters in order to manage the complexity of the existing building stock and to obtain a homogeneous set of aggregated data to be used as key indicators in large-scale interventions; 
- to provide decision support and fault diagnostic tools, that use models of regular operation (based on time series and statistic correction to identify abnormal events) integrated with support for simulation and what-if analysis;

- to define bottom-up interactive and interdisciplinary activities, adopting participatory design methods and tools, to raise awareness and acceptance of sustainable energy use and promoting behavioural change towards energy efficient sources and technology.

The main actions at district scale perform different approaches, depending on the urban context in which they are applied, but referring to those general strategies:

- heat-island mitigation, by acting on surfaces, green pavements and innovative façades materials, able to contribute to outdoor thermal and environmental comfort;

- water-management, by acting on greeneries, rain storage and also implementing positive and sustainable attitudes of end-users (for example by promoting the use of courtyard or roofs as urban vegetable gardens);

- data collection, by the implementation of technologies aiming at both simplifying people life (by acting on slow mobility, electrical mobility, intelligent traffic systems, intelligent parks systems) and collecting important information on the effects of the project and its possible improvements;

- $\quad$ people participation, by creating social and economic opportunities to boost a community identity, as well as co-creation and participation processes to implement refurbishment strategies.

\subsection{Interoperable platform for maps and data management}

To foster the development of a built environment transition strategy, an interoperable platform is proposed to support decision makers and stakeholders in selecting design solutions, priority of intervention, predictive maintenance programs, life cycle assessment, etc.

The platform is designed as a user-friendly tool able to provide data and analysis and to share knowledge and expertise between stakeholders and end users. In particular, the tools take into account:

- integration of smart metering devices and sensors installed within the building and management system at district level, monitoring indoor and outdoor conditions, energy consumption, user behaviour, and providing real time data to update a queryable GIS dashboard;

- assignment of digital ID to buildings and systems, in order to create active catalogues and data registry;

- creation of a management tool to supervise heating and cooling systems, energy generation, grids at neighbourhood scale, energy demand and peaks at district level;

- $\quad$ involvement of district communities and end users through ICT and apps;

- definition of a participatory design tool based on a socio-economic analysis at district scale; 
- identification of built environment refurbishment needs and opportunities, facilitating market growth and jobs creation.

In order to foster the change from high emission district to low carbon district, the platform provides a set of integrated refurbishment kits, tuned on clear and measurable parameters to be adapted and replicated in different contexts.

The refurbishment kits provide solutions combining excellent design concept and effective technical performances for the building envelope implementation, the grid optimization, the achievement of optimal comfort conditions, and the integration of interrelated tasks. The Refurbishment Kit is thought as a set of solutions that can be adapted, replicated and tuned to the specific site conditions in order to maximize their impacts at building and district scale, figure 3 . The tool aims at generating a positive impact on the quality of the built environment at urban scale, focusing on in between spaces as key-quality drivers.

\section{Impacts, replication models and conclusions}

The research aims to answer three principal needs:

- understanding the Smart City model complexity, by analysing how the different layers interact and how the building dimension could become an interconnection point among grids, power systems, monitoring systems and end-users;

- boosting the transition toward low carbon cities, assuming the district as optimized scale of intervention and the retrofitting of buildings and space between buildings as starting point;

- simplifying the interconnection among stakeholders, supplying fast and effective answers to common urban problems.

As a consequence, the methodology adopted by the project includes a first phase in which different strategies and case study are analysed in a critical way, followed by an applied research stage focusing on the specific context of Bologna and Mediterranean urban contexts.

\subsection{Monitoring as a support tool}

One of the ways to exploit the pervasive presence of ICT devices for useful issues is to withdraw information from them and collecting these data to feed management processes. The research plans the installation of different devices on buildings, such as sensors and data collectors, as well as semi-automatic knowledge dissemination systems. So the building is assumed not only as a comfortable system to housing people, but also as an interactive device able to play different actions:

- to collect data. Mainly aggregated data at building/district level are important to draw maps of the behaviour able to deep understand some important climate issues, as heat-islands, indoor and outdoor comfort, ventilation strategies, overheating analysis or solar gains strategies, water management; 


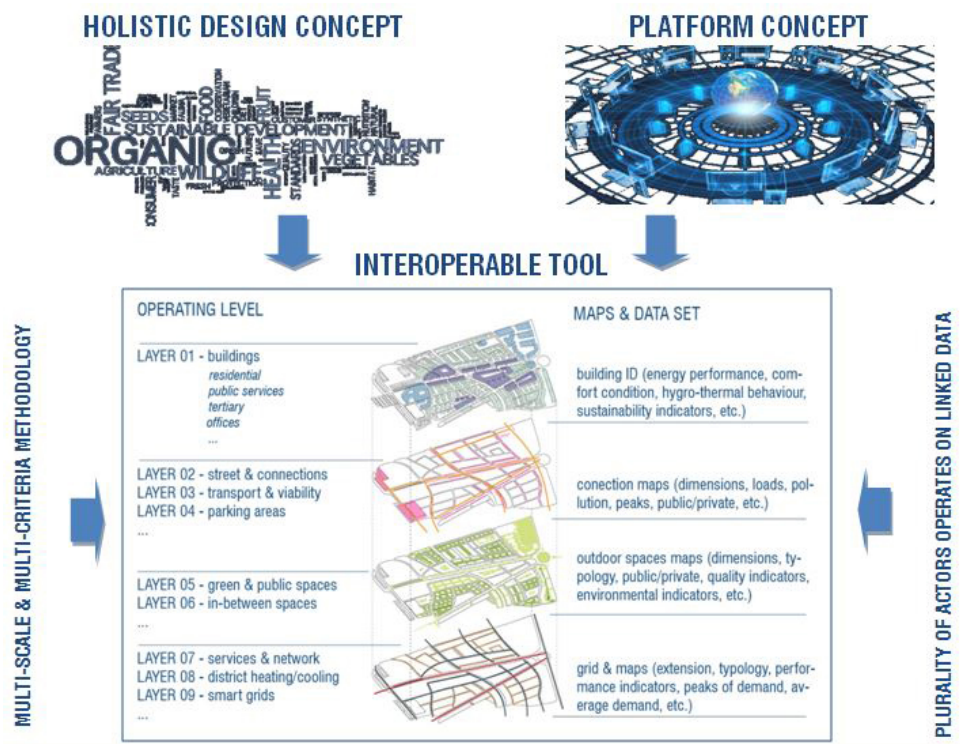

RENOVATION STRATEGIES \& INNOVATIVE SOLUTIONS
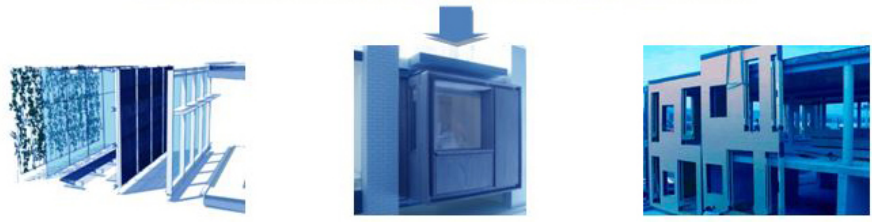

Figure 3: The Interoperable Tool is based on a multi-layer structure that is aimed to describe the complex and interrelated topics that are involved in the development of smart district/cities. The tool enables the management of several data set in order to optimize the design solutions to be delivered in each specific situation according to the needs in a balanced and sustainable vision.

- to manage data in an automatic or semi-automatic way. It becomes important that the building could act directly, without the human intervention, on some parameters (for example to limit overheating);

- to control actions. Data processing can allow different actions, done by endusers or building managers, or taken in automatic way;

- to share knowledge among end-users, in order to train people to better understand building and sustainable behaviour; and among stakeholders, in order to improve urban strategies and technologies.

\subsection{Impacts at different scales and replication}

Refurbishment actions at building and district level could bring excellent opportunities to reduce energy consumption and to encourage the adoption of 
other sustainable principles concerning citizens' healthcare, environment protection, rational use of resources and stakeholders groups' awareness. One of the project aims is the development of tools and methodologies able to accelerate refurbishment actions at district scale through user-friendly interfaces, costsavings solutions and integrated engagement of stakeholders. The main impacts expected by the use of this kind of instrument are the following:

- more communication and cooperation between stakeholders. The improvement of communication and cooperation between stakeholders could have an immediate positive impact in the short term and, at the same time, its achievement will provide long term outcomes;

- more effective time management. The project is also aimed at developing an open management system capable of supporting not only the design phases but also operation and maintenance at district scale as well. The adoption of faults diagnostic tools will allow to detect performance anomalies, system or equipment failures and to provide alert messages in order to boost prompt corrective measures. This dedicated tool is aimed to reduce faults, increase adequate reaction, maximize occupant comfort conditions and make buildings more economically competitive;

- more cost-effectiveness;

- more effective performance assessment;

- $\quad$ optimised design of integrated energy-efficient buildings, considering the different physical dimensions in a holistic perspective. An optimized design ensures an effective connection between the several aspects of the refurbishment action avoiding a number of different problems associated with the loss of key information generated during design phase, construction and operation;

- $\quad$ quantified performance objectives in compliance with regulation and useroriented comfort expectations and constraints.

\subsection{Conclusions}

The proposed methodology, as well as the platform, is assumed as a tool to support and address the development of the city vision. The process is based on a wide replication potential that invests several areas of the city after the pilots have been completed, as well as a number of similar cities in Italy and Europe where the tool set can be adapted for the specific context.

The envisaged methodology includes a number of different key parameters which are related to specific layers of information that the platform enables to manage with the goal to address the design and the development of the involved areas. This means the integration of ICT and conventional or innovative components represents the main driver to make the building smart increasing the connection level and providing access to several services and potential opportunities. Each single building can be associated to a sort of ID card that enable the platform to index information from different data set and the reaggregate data according to specific filters. This way specific strategies concerning energy behaviour, trends and demand as well as other key parameters can be developed and managed at district scale reshaping vast parts of the urban 
fabric by a systematic vision that keeps together any single intervention delivered at building scale.

Described methodology and tools try to provide an effective answer to the need of Municipalities to have the chance to connect information coming from different sources an investing the built environment at different scale so that to plan the most suitable option to profitably invest the available resources and maximize their impact at city level.

\section{References}

[1] IBM Institute for Business Value, Smarter city for smarter growth. How cities can optimise their systems for the talent-based economy, IBM Global Services, 2010.

[2] United Nation Population Fund (UNFPA), The state of world population 2011. People and possibilities in a world of 7 billion, USA, 2011.

[3] GIZ and ICLEI, Operationalizing the Urban NEXUS: towards resource efficient and integrated cities and metropolitan regions, GIZ Eschborn, 2014.

[4] ESPON, Third ESPON Synthesis Report. Territories finding a New Momentum: Evidence for Policy Development Growth and Investment, Luxembourg, 2014.

[5] Hajer M. and Dassen T., Visualizing the Challenge for $21^{\text {st }}$ Century Urbanism, Ed. naio10publisher/PBL publishers, Amsterdam, 2014.

[6] Kramers A., Hojer M., Lovenhagen N., Wangel J., Smart sustainable cities. Exploring ICT solutions for Reduced Energy Use in Cities, Environmental Modelling and Software, 56, pp. 52-62, 2014.

[7] Nam T, Pardo T., Conceptualizing Smart City with Dimension of Technology, People and Institutions, Proc. of the $12^{\text {th }}$ Annual Int. Digital Government Research Conf. on Digital Gov. Innovation in Challenging Times, 2011.

[8] European Environment Agency, Urban sprawl in Europe, the ignored challenge, Office for Official Publications of the European Communities, Luxembourg, 2006.

[9] Wolfram M., Deconstructing Smart Cities: an Intertextual Reading of Concepts and Practises for Integrated Urban and ICT Development, Proc. of REAL CORP 2012, pp. 171-181, 2012.

[10] Between spa, Smart City Index. Confrontarsi per diventare Smart, 2014, www.between.it

[11] Forum PA, ICity Rate 2014. La classifica delle città intelligenti italiane, 2014, www.forumpa.it

[12] Giffinger R., Fertner C., City ranking of European Medium-Sized Cities, Vienna University of Technology, University of Ljubljana, Delft University of Technology, 2007.

[13] European Commission, Energy Efficiency plan, Brussels, 2011.

[14] Smart City Council, Smart Cities Readiness Guide. The planning manual for building tomorrow's cities today, 2013. 